\title{
Ex-deportistas y publicidad. Análisis del caso español
}

Joaquín Marín Montín| jmontin@us.es

UNIVERSIDAD DE SEVILLA

Resumen: En la actualidad el deporte está presente en gran parte de los mensajes publicitarios. Tradicionalmente estos anuncios están protagonizados por grandes figuras del deporte en activo. Pero, en un momento de crisis como el actual, los ex-deportistas han adquirido un nuevo protagonismo. Este trabajo analiza su presencia en el panorama publicitario español reciente. El propósito de esta investigación es reconocer sus rasgos distintivos. El análisis se ha realizado sobre 8 anuncios entre 2011 y 2013, correspondientes a distintas firmas comerciales. Los resultados han permitido determinar qué valores propios encarnan los ex deportistas y su manera de presentarlos en la publicidad.

Palabras clave: ex-deportistas, publicidad, marca, valores

Abstract: Nowadays sports are present in many advertising messages. Traditionally most of these are made by famous sports icons that are active. But in these rough times of crisis many of ex-athletes are playing a new role. This paper analyzes their role in the recent Spanish advertising scenario. The main purpose of this research is focused in recognizing different features of these messages. The analysis was performed on 8 advertisements broadcasted between 2011 and 2013, focusing on eight major brands. This research showed what mostly of former athletes values are and how they present them in commercials and advertising field.

Key words: ex-athletes, advertising, brand, values 


\section{Introducción}

Desde que el deporte se convierte en actividad profesional, es habitual la presencia de deportistas en la publicidad. De esta forma, los medios de comunicación han permitido ensalzar el influjo del deportista estrella, cuya presencia especialmente televisiva ha generado un gran capacidad de influencia en la sociedad. $Y$ es que la actividad deportiva encarna una serie de valores, como el esfuerzo, el espíritu de superación, el respeto o el trabajo en equipo, que muchas marcas aprovechan estratégicamente apoyándose a través de la imagen del deportista. De esta forma, gracias a la publicidad el deportista "se promociona como figura a la que debe imitarse, y se fomenta un bien que produce estupendas inversiones para quienes lo fichan" (Alcoba, 2005: 23).

En su mayoría, estos mensajes publicitarios están protagonizados por destacadas figuras del deporte que gozan de una gran popularidad, como sucede en España con el tenista Rafa Nadal o el jugador de baloncesto Pau Gasol. Esta circunstancia permite aumentar en un alto grado la credibilidad en el consumidor al asociar el deportista a la marca. Sin embargo, este tipo de fórmula no es exclusiva del deporte sino que también forma parte de la publicidad testimonial, cuando es protagonizada por personas célebres o famosas fácilmente identificables por el público. De hecho, esta modalidad publicitaria suele tener un impacto inmediato, ya que logra envolver al producto con cualidades asociadas al personaje, permitiendo establecer una imagen personal. Así, estas personas conocidas llevan a cabo afirmaciones testimoniales para fomentar la venta de productos relacionados o no con su actividad profesional. Sirva como muestra, la campaña publicitaria de productos cosméticos L'Oreal que protagonizó en 2007 la actriz española Penélope Cruz. En este sentido, "es importante para el producto que el personaje tenga una imagen pública muy similar al producto publicitado. De esa manera se favorece la asociación entre marca y personaje" (García y Menéndez, 2007: 74).

Desde el punto de vista legal, este tipo de publicidad está sujeta a regulación. En el caso español, hay una ley específica sobre protección del derecho al honor, a la intimidad y a la propia imagen, que considera intromisión ilegítima si no está autorizada: "La utilización del nombre, de la voz o de la imagen de una persona para fines publicitarios, comerciales o de naturaleza análoga" (Ley Orgánica 1/1982: 12646). Otro aspecto que afecta a este tipo de mensajes hace alusión a la publicidad engañosa e ilícita que están recogidos en dos textos: la Ley 34/1988, de 11 de Noviembre, General de Publicidad; y en la Ley 3/1991, de 10 de Enero, de Competencia Desleal. Además de estas leyes en el marco español existe un sistema de autorregulación de la comunicación comercial, denominada Autocontrol que incluye un código de conducta publicitaria. En el mismo hay también una norma referida específica a la publicidad testimonial:

Cuando la publicidad incluya recomendaciones $\mathrm{y} / \mathrm{o}$ testimonios, esto es, aseveraciones de personas ajenas al anunciante y que no actúen como portavoces de éste, sean o no retribuidos, deberá responder a la verdad, tanto en cuanto a la 
persona del recomendante y/o testimoniante, cuanto acerca del contenido de la recomendación y/o del testimonio (Autocontrol, 2011: 6).

En los últimos años, se ha incrementado en España la aparición de ex-deportistas en los mensajes publicitarios, como nunca antes había sucedido. Los éxitos deportivos del deporte español en los últimos años han favorecido sin duda esta circunstancia. Se trata de personajes conocidos por un sector específico del público, que probablemente recuerde el periodo como deportistas en activo. Generalmente fueron deportistas que alcanzaron un gran éxito y proyectaron una imagen de confianza que años después continúa.

Pero este fenómeno no es exclusivo de España y es habitual también en otros países. Así por ejemplo en Estados Unidos, la figura de Michael Jordan asociada a distintas marcas llegó a alcanzar más desarrollo ya retirado que en su época de jugador, especialmente ligado a Nike. Otro nombre célebre de la historia del deporte, como es Pelé en Brasil ha llegado a convertirse en auténtico icono publicitario de importantes firmas como Pepsi o Mastercard. De esta forma, el reconocimiento social que el ex-deportista aún tenga, permite a los anunciantes acercarse a ellos. Además de sus logros deportivos cosechados en el pasado, es esencial el tipo de personalidad y carisma que les envuelve. Del mismo modo, las marcas aprovechan al máximo los valores positivos que como deportistas pudieron desarrollar para lograr mayor eficiencia en sus mensajes comerciales.

\section{Planteamientos de la investigación y metodología}

El principal objetivo de esta investigación se centra en reconocer los rasgos distintivos de los mensajes publicitarios protagonizados por ex-deportistas en el contexto español reciente. Además, con este trabajo se pretende determinar qué valores encarnan los ex-deportistas seleccionados frente los deportistas en activo. $Y$ finalmente, observar el tratamiento que el medio audiovisual hace del protagonista al presentar el producto.

El proceso de elaboración de este trabajo se ha basado en el método científico dentro del ámbito de las ciencias sociales. El estudio se enmarca desde una aproximación descriptiva e interpretativa basada en que las teorias son relativas debido a la multiplicidad de la realidad. La estrutura aplicada se ha basado en dos procedimentos: la revisión de la literatura y el análisis de contenido. Mediante el primero se ha buscado elaborar un breve marco teórico sobre la presencia de los ex-deportistas en los mensajes publicitarios. En segundo lugar, la aproximación a los mensajes se enmarca dentro de una metodología cualitativa basada en los datos proporcionados por la muestra que componen el corpus de este estudio.

De esta forma, el análisis se ha realizado sobre un muestra de ocho anuncios (v. Tabla 1), correspondientes a ocho firmas comerciales en las que aparecían hasta un total de nueve exdeportistas. Los anuncios fueron emitidos entre 2011 y primer semestre de 2013, cuya difusión se ha distribuido a través de televisión e Internet. 
Tabla 1 - Datos generales de la muestra

\begin{tabular}{|c|c|c|c|c|c|}
\hline Marca & Año & Producto/sector & Ex-desportista/s & $\begin{array}{c}\text { Edad en el } \\
\text { anuncio }\end{array}$ & $\begin{array}{c}\text { Deporte } \\
\text { Protagonista }\end{array}$ \\
\hline Regal & 2011 & Seguros & $\begin{array}{c}\text { Juan A. San } \\
\text { Epifaneo "Epi" }\end{array}$ & 52 años & Baloncesto \\
\hline $\begin{array}{c}\text { Banco } \\
\text { Popular }\end{array}$ & 2012 & Plan de pensión & Jesús Carballo & 36 años & Gimnasia \\
\hline $\begin{array}{c}\text { Banco } \\
\text { Sabadell }\end{array}$ & 2013 & $\begin{array}{c}\text { Cuenta } \\
\text { bancaria }\end{array}$ & $\begin{array}{c}\text { Luis Figo } \\
\text { Luis Enrique }\end{array}$ & $\begin{array}{c}41 \text { años } \\
43 \text { años }\end{array}$ & Fútbol \\
\hline Normon & 2012 & Farmaceútico & Manolo Santana & 75 años & Tenis \\
\hline BMW & 2012 & Coche & $\begin{array}{c}\text { Sheila Herrero } \\
\text { Juan M. López } \\
\text { Iturriaga }\end{array}$ & $\begin{array}{c}36 \text { años } \\
53 \text { años }\end{array}$ & $\begin{array}{c}\text { Patinaje de } \\
\text { velocidade }\end{array}$ \\
\hline Danacol & 2011 & Alimentación & Miguel Indurain & 47 años & Ciclismo \\
\hline Mapfre & 2012 & Seguro moto & $\begin{array}{c}\text { Angel Nieto } \\
\text { Jorge M. "Aspar" }\end{array}$ & $\begin{array}{c}65 \text { años } \\
50 \text { años }\end{array}$ & Motociclismo \\
\hline Somatoline & 2013 & Farmaceútico & Carlos Moyá & 36 años & Tenis \\
\hline
\end{tabular}

Además en este estudio se han valorado datos relacionados con el tratamiento audiovisual de los mensajes ( $v$. Tabla 2), permitiendo establecer conexiones y diferencias desde el punto de vista narrativo. El formato comercial mayoritario de los contenidos analizados corresponde al spot ${ }^{1}$, como género más difundido en publicidad.

"un spot es una pieza audiovisual realizada por encargo de un anunciante, que tiene una duración concreta; que se emite en espacios contratados con el objetivo de comunicar en mensaje comercial a un determinado grupo de personas llamado público objetivo, con el fin de despertar su interés hacia el produto, la empresa o servicio que se anuncia" (García-Clairac, 2005: 19).

Tabla 2 - Datos sobre la producción audiovisual de los anuncios

\begin{tabular}{|c|c|c|c|c|c|c|}
\hline Marca & Formato & Medio & Duración & No de planos & Localización & Otro \\
\hline Regal & spot & Televisión & $20 \mathrm{seg}$. & 14 & Interior & \\
\hline $\begin{array}{c}\text { Banco } \\
\text { Popular }\end{array}$ & Spot & Televisión & $30 \mathrm{seg}$. & 20 & Exterior & $\begin{array}{c}\text { Planos } \\
\text { áreos }\end{array}$ \\
\hline $\begin{array}{c}\text { Banco } \\
\text { Sabadell }\end{array}$ & Spot & Televisión & $40 \mathrm{seg}$. & 11 & Interior & B/N \\
\hline Normon & Spot & Televisión & $30 \mathrm{seg}$. & 16 & Virtual & Croma \\
\hline BMW & híbrido & Internet & $\begin{array}{c}3 \mathrm{~min} 50 \\
\mathrm{seg} .\end{array}$ & 70 & Exterior & \\
\hline Danacol & Spot & Televisión & $30 \mathrm{seg}$. & 14 & Exterior & Infografía \\
\hline Mapfre & Spot & Televisión & $30 \mathrm{seg}$. & 21 & Exterior & \\
\hline Somatoline & Spot & Televisión & $15 \mathrm{seg}$. & 11 & Exterior & Infografía \\
\hline
\end{tabular}

\section{Análisis de los anuncios}

A continuación se describen las características de cada uno de los ocho anuncios que componen el corpus estudiado, los cuales fueron selecionados según criterios de popularidad, disponibilidad y variedad en cuanto al deporte reflejado.

\footnotetext{
${ }^{1}$ Su duración se encuentra entre 10 segundos y 1 minuto. Formatos más comunes: 10, 20, 30 y 60 segundos.
} 


\subsection{Regal - Epi}

Este anuncio está creado por la agencia Pavlov y producido por Cannon Ball. La marca Regal corresponde a una compañía aseguradora, cuya actividad se centra en el seguro de coche, motor, hogar y vida. Regal es además actualmente el espónsor oficial de la sección de baloncesto del FC Barcelona. El spot está protagonizado por Juan A. San Epifáneo "Epi". Su figura está asociada a una brillante trayectoria como jugador de balocesto en la que desarrolló toda su carrera en el FC Barcelona, cuyo número 15 en la camiseta dejó de usarse cuando se retiró. Entre sus diferentes éxitos destaca la medalla de plata lograda en los Juegos Olímpicos de Los Angeles 1984. Fue el último relevista de la antorcha olímpica en los Juegos Olímpicos de Barcelona en 1992. Se le concedió la orden del Mérito Olímpico. Durante sus 19 años como jugador, nunca tuvo un comportamento antidesportivo: "cualidades que le convirtieron en 'Superepi': la motivación, el afán de superación, el espíritu de lucha, la capacidad de cooperar y trabajar en equipo y algo, muy importante, la humildad para aprender de las derrotas y seguir adelante" (Velasco, 2001: 301).

Todos estos elementos permitieron al anunciante construir un mensaje combinando los valores del protagonista altamente reconocidos socialmente con los de la aseguradora. Además, la difusión del anuncio estaba dirigida al ámbito catalán. Como señala Paco Robles, "la marca Regal siempre ha estado ligada a Cataluña y Cataluña forma parte de su ADN"2. Desde el punto de vista de la producción, se trata de un spot televisivo de 20 segundos, si bien la campaña incluía versiones de 10 segundos. La pieza selecionada para este análisis está localizada en el Palau Blaugrana, escenario deportivo real y estructurada en 14 planos. Narrativamente muestra a Epi a sus 52 años, lanzando a canasta en cuatro ocasiones a la vez que pronuncia breves mensajes relacionados con la marca. Tras el cuarto tiro, que lanza de espaldas y falla, se dirije al banquillo. Una vez sentado pasa el balón al quintento de jugadores del equipo titular en 2011 (Navarro, Fran Vázquez, Victor Sada, Pete Mickeal y Chuck Eidson) con el que finaliza el anuncio.

\subsection{Banco Popular - Jesús Carballo}

La agencia $R^{*}$ fue la encargada de desarrollar la campaña publicitaria del plan de pensiones del Banco Popular y producido por Puente Aéreo. La campaña incide especialmente en los valores de seguridad y cercania que la entidad busca transmitir a sus clientes con un nuevo plan de pensiones. Para su desarrollo completo, se optó por un conjunto de antiguas figuras del deporte español ${ }^{3}$, que fueran cercanas y accesibles. El spot elegido para este trabajo está protagonizado por Jesús Carballo, destacado ex-gimnasta español. Carballo ha competido en

\footnotetext{
2 "Arranca la nueva campaña de Regal protagonizada por Epi". Noticias Canal Directo de Liberty Seguros, Barcelona, en http://www.regal.es/seguros-regal/campanaregalepi (consultado: 02 abril 2013).

${ }^{3}$ El ex-jugador de baloncesto Fernando Romay, el ex-atleta Fermín Cacho, la ex-esquiadora Blanca Fernández Ochoa, y el ex-jugador de fútbol Juan Señor.
} 
la disciplina de gimnasia deportiva y está considerado uno de los más destacados a nivel internacional. Como desportista fue dos veces campeón del mundo en la modalidad de barra fija en 1996 y 1999. Formó parte de la selección en los Juegos Olímpicos de Atlanta en 1996. A pesar de la escasa repercusión mediática de su deporte en España, Carballo fue un desportista carismático y reconocido socialmente.

En cuanto a la producción del spot seleccinado, tiene una duración de 30 segundos, aunque al igual que en el caso anterior incluía versiones de menor duración. Uno de los aspectos más llamativos del anuncio es su localización, ya que está filmado en exteriores en medio de un paisaje natural semidesértico ubicado en el parque natural de Bardenas Reales en Navarra. En el mismo se instaló un aparato de anillas al que el ex-gimnasta se apoya aunque sin actuar en ella para exponer el mensaje publicitario. En el spot aparecens planos aéreos en los que se sitúa de forma aislada el personaje. La pieza está compuesta de 20 planos y se caracteriza por un ritmo pausado que transmite a través de las imágenes y sonidos sensaciones de armonía y confianza. Desde el punto de vista narrativo, el anuncio incluye imágenes suyas de archivo cuando competía en las que Carballo hace alusiones a su entrenador Hector, y a la seguridad que le transmitia. Precisamente esta seguridad es la que le sirve para enlazar directamente con el eslogan del plan de pensión, haciendo mención a su futuro.

\subsection{Banco Sabadell - Luis Figo / Luis Enrique}

Este anuncio fue ideado por la agencia SCPF desarrollada para el Banco Sabadell y producido gráficamente por We Folk. Forma parte de una campaña que lleva el título de "Nuevos Clientes" lanzada a pimcipios de 2013 destinada a conseguir clientes en la Cuenta Expansión. En la misma, se utiliza el concepto de cambio como hilo conductor y se articula en una serie de entrevistas que la periodista Julia Otero realiza a conocidos personajes, provenientes de diferentes ámbitos. El elemento común de todos ellos se ha basado en el cambio, como concepto esencial de su trayectoria profesional. La pieza selecionada para este trabajo está protagonizada conjuntamente por los ex-futbolistas Luis Figo y Luis Enrique. Ambos personajes comparten el hecho de haber jugado en los dos equipos de fúbol españoles más importantes. En un momento de sus vidas, tomarían la polémica decisión de cambiar de club. Concretamente del FC Barcelona a Real Madrid en el caso de Figo y de Real Madrid a FC Barcelona en el caso de Luis Enrique.

Precisamente en torno a este asunto se desarrolla la pieza analizada que forma parte de la campaña difundida en distintos medios y formatos. Desde el punto de vista de la producción, se trata de un spot de 40 segundos rodado en blanco y negro en un set de televisión. El formato utilizado es la entrevista articulado en 11 planos, que según señalan sus creadores "además de aportarnos una novedad formal, nos interesaba mucho profundizar en los distintos cambios que han vivido los personajes que la protagonizarán y la entrevista es, sin duda, un extraordinario medio para ello" (Control de Publicidad, 2013). Desde el punto de vista narrativo, divide el mensaje en tres partes: la primera que introduce la periodista Julia Otero señala el elemento común de los protagonistas, a continuación cada 
uno de ellos justifica el motivo del cambio. Y será esta idea de cambio la que enlace con el eslogan de cierre del anuncio.

\subsection{Normon - Manolo Santana}

Se trata de un anuncio creado por las agencias Yperfom y Circus Marketing. La firma Normon es una compañía especializada en productos farmacéuticos que abarca desde medicamentos, productos de nutrición infantil, de línea dental así como de autocuidado de la salud. El pasado 2012 cumplió su 75 aniversario y aprovechó para lanzar un campaña publicitaria eligiendo a una persona de renombre. El protagonista del spot es el ex-tenista Manolo Santana que precisamente cumpliría la misma edad de la firma comercial. Santana ha sido un destacado deportista español en la década de los 60 y que cuenta con un brillante palmarés ganando cuatro torneos de Gran Slam. Fue uno de los grandes impulsores del deporte de la raqueta en España. Desde el punto de vista de la producción, es un spot de 30 segundos. El concepto creativo de la pieza presenta a un deportista que se sumerge en un ambiente futurista e inovador cargado de fuerza y energia. Para lograr tal efecto se caracterizó al tenista con un traje especial. Desde el punto de vista técnico, el anuncio tiene 16 planos y fue rodado en un set virtual con movimentos de grúa y travelling. A nível de postproducción se insertaban diferentes imágenes entre las que incluía la del tenista en su etapa de jugador. Desde el punto de vista narrativo, el mensaje de la pieza se construye a partir de las descripciones del protagonista en la que justifica su éxito gracias al cuidado y la innovación continua, que le permiten alcanzar los 75 años.

\subsection{BMW - Sheila Herrero}

Este anuncio fue creado en 2012 por la agencia SCPF junto a la productora CP Works. Forma parte de la campaña denominada "Alma de ganador", en la que Juan M. López Iturriaga entrevista a distintos ex-deportitas españoles que lograron grandes triunfos. La campaña del nuevo BMW Serie 3 se inspira en diferentes historias de superación de deportistas como Pedro Delgado, Abel Antón y Theresa Zabell. Se trataba de relacionar valores que estos desportistas encarnan como sufrimiento, el coraje, el valor, el sacrifício y la superación a la marca de vehículos alemana.

La pieza selecionada para el análisis corresponde a un género híbrido más cercano por su contenido al branded content ${ }^{4}$ que al spot convencional. El anuncio está protagonizado por Sheila Herrero, ex-patinadora profesional de velocidad y deportista española que más galardones ha logrado por encima incluso de deportistas masculinos. Herrero ha sido 15 veces campeona del mundo y logrado 136 títulos europeos. Ha obtenido diferentes reconocimientos destacando entre otros la Medalla de Oro al Mérito deportivo en el año 2000. Con este palmarés, se presenta la protagonista de este anuncio que conversa con otro ex-deportista como es Iturriaga que hace de interlocutor mientras conduce el nuevo vehículo

\footnotetext{
${ }^{4}$ Nueva forma publicitaria cercana al entretenimento y utilizada en nuevos medios como Internet.
} 
BMW. La pieza tiene una duración cercana a los 4 minutos en el que encontramos hasta un total de 70 planos. El anuncio está localizado por escenarios conocidos por la protagonista en los que obtuvieron éxitos pasados repartidos entre la carretera y las pistas. Desde el punto de vista narrativo, a medida que conversan los dos personajes, la protagonista va recordando diferentes momentos de su carrera. Así a medida que Sheila Herrero va contando sus recuerdos se insertan imágenes suyas en diferentes momentos de la competición. En el penúltimo plano del anuncio se inserta unos créditos que resume los éxitos de la deportista y a continuación el nombre de la marca y una alusión a la campaña publicitaria antes referida.

\subsection{Danacol - Miguel Induráin}

En este caso, se trata de un anuncio del sector alimentario creado por la agencia Vinizius Y\&R y cuya realización audiovisual fue desarrollada por la productora Ovideo. Danacol es un producto de la multinacional francesa de derivados lácteos Danone. La campaña procura incidir en el valor preventivo de un producto que ayuda a reducir el colesterol. Desde que lanzó el artículo, su difusión comercial se apoyó en personajes relevantes españoles de diferentes ámbitos con los que se pretendia asociar el consumo del producto, como el cantante Manolo Escobar o más recientemente el seleccionador Vicente del Bosque. El spot elegido para este trabajo está protagonizado por el ex-ciclista Miguel Indurain. Se trata de uno de los mejores deportistas españoles de todo los tiempos. De sus triunfos destaca especialmente haber sido ganador del Tour de Francia durante cinco años consecutivos, del Giro de Italia en dos ocasiones así como haber ganado la medalla de oro en los Juegos Olímpicos de Atlanta 96. Su figura está altamente reconocida y valorada socialmente. Además entre otros galardones destacados obtuvo el Premio Príncipe de Asturias de los Deportes en 1992.

En cuanto a la producción de la pieza seleccionada, se trata de un spot de 30 segundos, aunque como en casos anteriores la parte audiovisual de la campaña incluía versiones de menor duración. El anuncio está ubicado en localizaciones naturales, correspondiente a carreteras de montaña habituales en las pruebas ciclistas. Además en el spot se apoya en infografía para ilustrar gráficamente el colesterol. Desde el punto de vista narrativo, aparece inicialmente Indurain montando en bicicleta hasta detenerse. A partir de este momento el ex-deportista se dirije a cámara y explica los riesgos del colesterol comparándolo con los del ciclismo cuando la carretera se estrecha. En la mitad del anuncio se insertan una animación creada por ordenador representando al colesterol. En la parte final de la pieza aparece nuevamente en imagen la figura Indurain incidiendo en los benefícios del producto con el que afirma indentificarse.

\subsection{Mapfre - Angel Nieto / Jorge M.Aspar}

Se trata de una pieza publicitaria desarrollada por la agencia Mc Erickson para la firma aseguradora Mapfre. El anuncio forma parte de la campaña denominada "Pandilleros" destinada al seguro de motos. La idea del anuncio es mostrar como dos pilotos se enfrentan 
a un grupo de pandilleros, por haber tirado una de sus motos. Para ello, se acudió a dos expilotos de motociclismo, Ángel Nieto y Jorge Martínez "Aspar". Al igual que en los casos anteriores, la campaña se vale de dos referentes del mundo del deporte. Por un lado, Ángel Nieto tiene un brillante palmarés con 13 títulos mundiales en diferentes categorías de motociclismo, y ha recibido destacados reconocimientos como la Orden Olímpica y la Gran Cruz de la Real Orden al Mérito Deportivo. Por su parte, Jorge Martínez ha sido cuatro veces campeón del mundo e igualmente ha obtenido diferentes galardones entre la que destaca especialmente la Medalla de oro de la Real Orden del Mérito Deportivo.

En cuanto a la producción del spot, tiene una duración de 30 segundos en línea con el formato televisivo estándar. Desde el punto de vista de la realización la pieza está compuesta de 21 planos. La acción está localizada de noche en la puerta de un clásico bar de carretera. Desde el punto de vista narrativo, el anuncio relata el enfrentamiento entre los dos ex-deportistas y un grupo de pandilleros que tiran la moto de Ángel Nieto. El spot incide especialmente en la fortaleza del motero, representada por los dos protagonistas pero no de la moto y a la que Mapfre ofrece solución en caso necesario como sucede en el anuncio, remarcando el trato personal de la aseguradora. Como en otros mensajes de la compañía, el anuncio finaliza con el eslogan "Así es Mapfre, personas que cuidan de personas" pronunciado por Ángel Nieto.

\subsection{Somatoline - Carlos Moyá}

Cierra la muestra de esta investigación, el spot más reciente de todos los anuncios seleccionados. Esta pieza fue desarrollada por la agencia Kohl y producida por Filmmaster para la marca italiana Somatoline Comestic. El anuncio forma parte de su línea masculina de productos dedicados al cuidado personal. La firma ha estado orientada en su mayor parte hacia un target femenino especialmente como tratamiento para ayudar a combatir la celulitis. El protagonista del anuncio elegido es el ex-tenista Carlos Moyá, retirado de la alta competición en 2010. Moyá ha sido un destacado tenista que durante cinco años llegó a estar entre los diez mejores del mundo, siendo número uno en 1999. En cuanto a la producción del spot, fue filmada en Milán, bajo la dirección de Fabrizio Mari y la fotografia de Manfredo Archinto. La pieza forma parte del esquema internacional que la marca utilizó con otros deportistas de renombre, como el esquiador italiano Giorgio Rocca. La duración del anuncio es de 15 segundos y está estructurado en un total de 11 planos. En la primera parte incluye imágenes de archivo del ex-deportista cuando jugaba, que van acompañadas de un rótulo que informa que fue N01 del ranking ATP en 1999. En cuanto a la localización se desarrolla en una habitación en la que se aprecia un espejo en la que se refleja el protagonista y una cama en la que aparece durmiendo. Desde el punto de vista narrativo, el mensaje incide en la alta actividad física que muchos hombres actuales tienen, precisando de un complemento que le permita reducir la grasa y tonificar la piel en la zona abdominal. Así las primeras palabras de Moyá en el anuncio son: "como desportista busco grandes resultados incluso cuando quiero reducir". A continuación aparece en un primer plano la imagen del producto a la que sigue una breve infografía sobre el área del cuerpo sobre la 
que actúa. El anuncio finaliza con una nueva afirmación del ex-tenista "rápido y directo al resultado" que enlaza con el eslogan "Somatoline Cosmetic Hombre Funciona".

\section{Resultados y discusión}

Una vez descritas las características de los ocho anuncios, vamos a señalar sus elementos más destacados. A partir de la muestra analizada, se detecta como los mensajes publicitarios de las 8 marcas protagonizados por figuras retiradas del deporte forman parte del género testimonial aunque con algunos matices. El público objetivo de los anuncios guarda una estrecha relación con el conocimiento que tenga del ex-deportista. En este sentido, la identificación del público con el deportista aumentará si existe una mayor cercania generacional. Por ello, la edad del protagonista influye en el tipo de producto anunciado tal como aparece reflejada en la Tabla 1.

En segundo lugar, hay que hacer mención a los valores como un componente esencial de estos mensajes. Al igual que en la publicidad protagonizada por desportistas en activo, en los 8 anuncios analizados se constata claramente la presencia de los valores (v. Tabla 3). Uno de los valores más repetidos en el análisis son la seguridad y el esfuerzo. A diferencia de los anuncios de deportistas en activo, el argumento que más predomina en los anuncios investigados son elementos que permitan generar por encima de todo confianza, avalados por la experiencia de los testimonios presentados. Los propios ex-deportistas refuerzan los mensajes publicitarios con sus propias palabras.

Finalmente, en cuanto al tratamento audiovisual de los anuncios son producciones por lo general bien elaborados. Así, las 8 piezas están diseñadas por destacadas agencias españolas de publicidad con una línea creativa cuidada y realizados por productoras de primera fila incluso a nível internacional. En cuanto a los escenarios presentados, tal como se indica en la Tabla 2, cuatro de ellos utilizan localizaciones exteriores y el resto en interiores (tres en set de televisión y una en un recinto deportivo). En lo referente a la edición, tres de los ocho anuncios analizados hacen uso de la infografía para apoyar los mensajes. Igualmente es muy indicativo como 4 de los 8 anuncios insertan imágenes de archivo del deportista cuando competía. De esta forma se refuerza el valor del testimonio del protagonista en el mensaje publicitário. Además en dos anuncios aparecen los protagonistas ejecutando en el tempo presente una acción deportiva (Epi lanzando a canasta e Indurain sobre la bicicleta). 
Tabla 3 - Datos sobre la presencia de valores del deporte

\begin{tabular}{|c|c|c|c|c|c|c|c|c|}
\hline & $\begin{array}{l}\text { Epi } \\
\text { (Regal } \\
\text { ) }\end{array}$ & $\begin{array}{l}\text { J.Carballo } \\
\text { (Banco } \\
\text { Popular) }\end{array}$ & \begin{tabular}{|l} 
L.Enrique/ \\
L.Figo \\
(Banco \\
Sabadell)
\end{tabular} & $\begin{array}{l}\text { Manolo } \\
\text { Santana } \\
\text { (Normon) }\end{array}$ & \begin{tabular}{|l} 
Sheila \\
Herrero \\
$(\mathrm{BMW})$
\end{tabular} & $\begin{array}{l}\text { Indurain } \\
\text { (Danacol) }\end{array}$ & $\begin{array}{l}\text { Angel } \\
\text { Nieto } \\
\text { /Aspar } \\
\text { (Mapfre) }\end{array}$ & $\begin{array}{l}\text { C. Moyá } \\
\text { (Somatoline) }\end{array}$ \\
\hline Seguridad & $\mathrm{X}$ & $\mathrm{X}$ & $\mathrm{X}$ & $\mathrm{X}$ & & $\mathrm{X}$ & $\mathrm{X}$ & $\mathrm{X}$ \\
\hline Compañerismo & $\mathrm{X}$ & $\mathrm{X}$ & & & & & $\mathrm{X}$ & \\
\hline Esfuerzo & $X$ & $\mathrm{X}$ & $\mathrm{X}$ & $\mathrm{X}$ & $\mathrm{X}$ & $\mathrm{X}$ & & $\mathrm{X}$ \\
\hline Perfección & $\mathrm{X}$ & $\mathrm{X}$ & & & $X$ & & & \\
\hline Disciplina & $X$ & $\mathrm{X}$ & & $\mathrm{X}$ & $\mathrm{X}$ & & & $\mathrm{X}$ \\
\hline Riesgo & & $\mathrm{X}$ & $\mathrm{X}$ & & $X$ & & $\mathrm{X}$ & \\
\hline Coraje & & & $X$ & & $X$ & & $\mathrm{X}$ & \\
\hline Superación & & $\mathrm{X}$ & & & $X$ & & & \\
\hline Prevención & $\mathrm{X}$ & $x$ & & $\mathrm{X}$ & & $x$ & $\mathrm{x}$ & $x$ \\
\hline Vida sana & & & & $\mathrm{X}$ & & $\mathrm{X}$ & & $x$ \\
\hline
\end{tabular}

\section{Conclusiones}

A lo largo de este trabajo, se ha constatado la importancia que el deporte tiene para la publicidad actual. Sin embargo, los protagonistas son además ahora estrellas del deporte que ya no están en activo. Durante la investigación se ha detectado como los valores del deporte siguen están muy presentes para la elaboración de los mensajes publicitarios analizados en el ámbito español.

La elección de los protagonistas está determinada no sólo por sus logros deportivos sino también el tipo de personalidad y carisma que los envuelve. Y es que las firmas comerciales aprovechan al máximo los elementos positivos que el deporte les genera para promocionar sus productos. Pero no todos los deportistas que estuvieron en activo que incluso fueron grandes inconos publicitarios interesan a las marcas una vez ya retirados. Por ello, para la publicidad confiar en ex-deportistas para protagonizar sus anuncios les obliga a plantear una estrategia diferente frente al deportista que está en primera línea activa de su carrera.

El tipo de público objetivo es ahora diferente y exige un tratamiento en el que se describan otros aspectos. Así ahora el target debe saber reconocer en el mensaje comercial los valores que el protagonista tuvo como deportista para poder eficazmente asociarlo al tiempo presente. De ahí que muchos de estos anuncios se apoyen en las imágenes de archivo para ayudar a refrescar la memoria del espectador sobre los éxitos que los protagonistas lograron cuando eran grandes iconos como desportistas en activo.

Desde el punto de vista audiovisual, se detecta en general un ritmo más pausado en este tipo de anuncios frente a los mensajes comerciales de las grandes estrellas deportivas que están en primera línea de actualidad. Además el componente emocional suele estar ahora 
mucho más presente en los anuncios analizados, en los que se opta incluso por mirar hacia atrás de una manera melancólica. El ejemplo más claro se observó en los anuncios de los planes de pensiones Finalmente, este trabajo permitirá plantear futuras investigaciones comparativas con otros contextos y países con objeto de detectar elementos nuevos y ver si están tan presentes como en la publicidad española actual.

\section{REFERENCIAS BIBLIOGRÁFICAS}

AlcobA, Antonio (2005): Periodismo deportivo. Madrid, Síntesis.

Autocontrol (2011): "Código de conducta publicitaria" en Asociación para la Autorregulación de la Comunicación Comercial, p.6, en http://www.autocontrol.es/pdfs/Cod_conducta_publicitaria.pdf (consultado: $18 / 02 / 2013)$

Control de Publicidad (2013): "Banco Sabadell ficha a Julia Otero" en http://controlpublicidad.com/2013/02/11/banco-sabadell-ficha-a-julia-otero (consultado: 29/03/2013).

DUNNING, Enric (2003): El fenómeno deportivo. Barcelona, Paidotribo.

FERNÁNDEZ, Jorge David (2005): Aproximación a la estructura de la publicidad. Sevilla, Comunicación Social.

García, María Luisa y MenÉndez, TANiA (2007): Fundamentos de la realización publicitaria. Madrid, Fragua: Aproximación a la estructura de la publicidad. Sevilla, Comunicación Social.

García-Clairac, Santiago (2005): Realización de spots publicitários. Córdoba, Almuzara.

LEY 34/1988, de 11 de Noviembre, General de Publicidad. Boletín Oficial del Estado, n.274, 14 noviembre 1988. Texto consolidado, 27 de diciembre 2012, pp. 1- 8 .

LEY 3/1991, de 10 de Enero, de Competencia Desleal. Boletín Oficial del Estado, n.10, 11 enero 1991. Páginas 959 a 962 (4 págs.).

LeY Orgánica 1/1982, de 5 de mayo, de Protección Civil del Derecho al Honor, a la Intimidad Personal y Familiar y a la Propia Imagen. Boletín Oficial del Estado, n.115, 14 mayo 1982, pp. 12546-12548.

LOREDO, Alba (2013): "El deporte como espejo donde anunciarse" en El Mundo, Madrid, pp.16-18. 
MARÍN, Joaquín (2010): "Valores mediáticos del deportista profesional en la publicidad. Análisis comparativo entre Rafa Nadal y Gemma Mengual" en Comunicación. Revista Internacional de Comunicación Audiovisual, Publicidad y Estudios Culturales, vol.1, no8, pp. 26-40, en: http://www.revistacomunicacion.org/pdf/n8/articulos/A3_Valores_mediatico s_del_deportista_profesional_en_la_publicidad_analisis_comparativo_entre_ rafa_nada_y_gemma_mengual.pdf (consultado: 07/03/2013).

VeLASCO, Asunción (2001): "La perspectiva de expansión y empleo", en Sáenz de Miera, A.: En torno al trabajo universitario: reflexiones y datos. Madrid, Ministerio de Educación, Cultura y Deporte, pp. 301-302.

[Recibido: 24 de octubre de 2014. Aceptado: 16 de noviembre de 2015] 